\title{
Experimental and Simulation Research of AC Ripple Losses in a High Temperature Superconductor Tape
}

\author{
Hongwei Liu (D, ${ }^{1,2}$ Guosheng Song, ${ }^{1,2}$ Chuanhui Zhang, \\ Jinwen Tan, ${ }^{1,2}$ and Wengang Feng ${ }^{1,2}$ \\ ${ }^{1}$ Key Laboratory of HV and EMC Beijing, Beijing 102206, China \\ ${ }^{2}$ School of Electric and Electronic Engineering, North China Electric Power University, Beijing 102206, China \\ Correspondence should be addressed to Hongwei Liu; hwliu@ncepu.edu.cn
}

Received 17 November 2017; Revised 18 January 2018; Accepted 4 March 2018; Published 17 April 2018

Academic Editor: Gayanath Fernando

Copyright (C) 2018 Hongwei Liu et al. This is an open access article distributed under the Creative Commons Attribution License, which permits unrestricted use, distribution, and reproduction in any medium, provided the original work is properly cited.

Current leads in superconducting magnets are widely adopted for heavy current transmission, and HTS DC cables have great advantages when used as current leads for such purposes. However, as an important parameter of HTS DC cables, AC loss has a strong impact on the stability and operation cost of current leads. In this paper, experiments were conducted to measure AC ripple losses of HTS tapes and HTS cables, and simulations of HTS tapes were carried out. The paper has reached conclusions on the relation between $\mathrm{AC}$ losses and power frequencies.

\section{Introduction}

Current leads are among the most important components in superconducting equipment, such as superconducting electric apparatus and superconducting magnets. Generally, high temperature superconductors (HTS) are widely used as current leads, as they may reduce heat leakage along current leads from room temperature to liquid nitrogen or liquid helium. Bi-2223-based hybrid current leads have been used extensively in accelerators and superconducting magnets [1]. Recently, 2G coated conductors have been reported for current leads (CL) application [2], demonstrating the feasibility of HTS tapes for CL application. Although DC current is always applied to the magnets and accelerators, AC ripple currents exist simultaneously with DC current during the transient processes of excitations and deexcitations, thus incurring AC Losses in the HTS tapes. ACloss is an important factor for HTS electric equipment in that it determines the capacity of the accompanying cryogenic cooling system [3]. References [3-7] have experimentally researched the AC loss behavior of superconducting tapes under $\mathrm{AC}$ ripple superimposed on a DC offset current, providing useful guidance for the evaluation of AC losses when the DC and AC ripple currents exist simultaneously. References [8-13] provide some measuring methods of AC losses, but the applied frequencies of AC ripple currents are not typical in actual power systems.

This paper aims to research experimentally AC ripple current losses of HTS tapes and the HTS cable for the common frequency range in the actual power system. Simulations of HTS tapes were also carried out under this study. The applied AC ripple current was the odd multiples of basic frequency. AC losses were measured under different amplitudes of $\mathrm{AC}$ currents and at different frequencies. Moreover, in the experiment, DC currents were the most part, while AC ripple currents were a small part of the total current, which is more consistent with superconducting electric DC equipment in reality. At the end of the paper, experiment data was provided and analysis was given about the causes for the phenomena.

\section{Experimental Setup}

2.1. Parameters of the YBCO Tape. The YBCO superconductors are made by Suzhou Advanced Materials Research Institute, and their critical current is $60 \mathrm{~A}$ at $77 \mathrm{~K}$. The width is $2.5 \mathrm{~mm}$, and the thickness is $0.18 \mathrm{~mm}$. The specification of the superconductor was listed in Table 1. Although the critical current of the YBCO tape was a little lower, it was fit for the 
TABLE 1: Specification of the superconductor.

\begin{tabular}{lc}
\hline Electric parameter & \\
\hline Width & $2.5 \mathrm{~mm}$ \\
Thickness & $0.18 \mathrm{~mm}$ \\
Critical current & $60 \mathrm{~A}$ \\
\hline
\end{tabular}

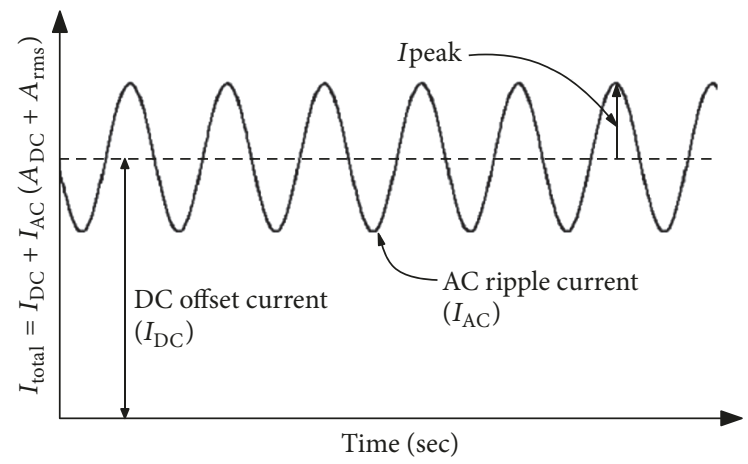

FIGURE 1: The schematic picture of the total current which includes the DC current and the AC ripple current.

experiments because of the capacity limit of the adjustable capacitor.

First, the critical characteristics of the HTS tape were measured, and the results were highly consistent with the critical current. Then we set up the experimental platform at which the AC losses were measured under the DC and AC ripple currents. The total current was shown in Figure 1, where we used the amplitude values for AC currents [5]. Thus, the total current is the sum of the DC current and the amplitude of the AC current.

2.2. Experimental Setup. In order to generate the hybrid source signal, a DC current source and an AC current source were paralleled. An adjustable capacitor was used in case the DC current might circulate to the branch of the AC current source. During the experiments, a fixed DC current was set to the HTS tape. Then, we changed the frequency of the AC current source to the set value. At the same time, the capacitor was adjusted because of the change of frequency. A lock-in amplifier was used to find the in-phase component of the voltage. In the experiment, we measured the frequency of $50 \mathrm{~Hz}, 150 \mathrm{~Hz}, 250 \mathrm{~Hz}$, and $350 \mathrm{~Hz}$. They are the odd multiples of the basic frequency and the most typical frequency components in the power system and the electric equipment. Every time the data acquisition system recorded the data for the following analysis. Figure 2 showed the schematic experimental platform and Figure 3 showed the real experiments photos. Since the critical current is $60 \mathrm{~A}$, the highest total current we applied was 1.2 times $I_{c}$, that is, $72 \mathrm{~A}$. The AC current was measured by the Rogowski coil and the total current by the shunt resistor.

\section{Experimental Results}

First, we fixed the DC current to $45 \mathrm{~A}$. Then we increased the AC current step by step from $5 \mathrm{~A}$ to $27 \mathrm{~A}$ at a fixed frequency.

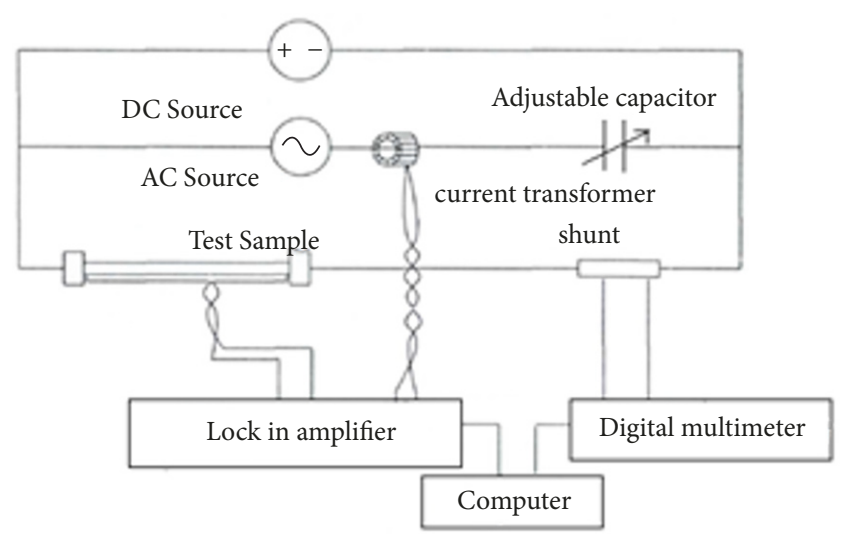

FIGURE 2: The schematic experimental platform.

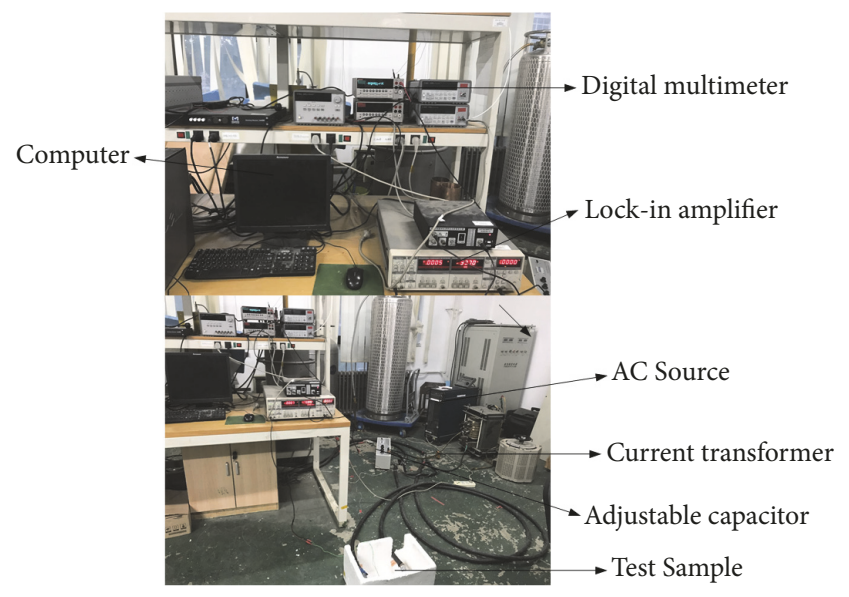

Figure 3: The real experimental photos.

Figure 4 showed the result of AC losses with the DC current of $45 \mathrm{~A}$ and the different amplitude of $\mathrm{AC}$ currents at the frequency of $250 \mathrm{~Hz}$ and $350 \mathrm{~Hz}$. From the result, we could see that the AC losses increased with the amplitude of the AC current. When the total current approached $72 \mathrm{~A}$, the losses increased greatly compared with that of $50 \mathrm{~A}$. Figure 4 also showed that the AC loss was irrelevant to the frequency.

Figure 5 showed that, at a fixed AC current, the AC losses only slightly increased with the increase of the frequency. It signified that the AC losses were not much related to the frequency from $50 \mathrm{~Hz}$ to $350 \mathrm{~Hz}$. On the other hand, the amplitude of the AC current had much more impact on the AC losses. With the increase of the amplitude of the AC current, the AC losses increased prominently.

Then, we fixed the DC current at $55 \mathrm{~A}$. With the same steps as previously, we got the results as Figures 6 and 7 showed. We can see that the AC losses slightly increased with the frequency when the total current was $60 \mathrm{~A}$. And the amplitude of the AC current had more effect on the AC losses. In order to research the effect of the DC current and the AC ripple current, we changed the different component of the total current while keeping the total current fixed. Figure 8 showed the experimental result. It showed that, at the same 


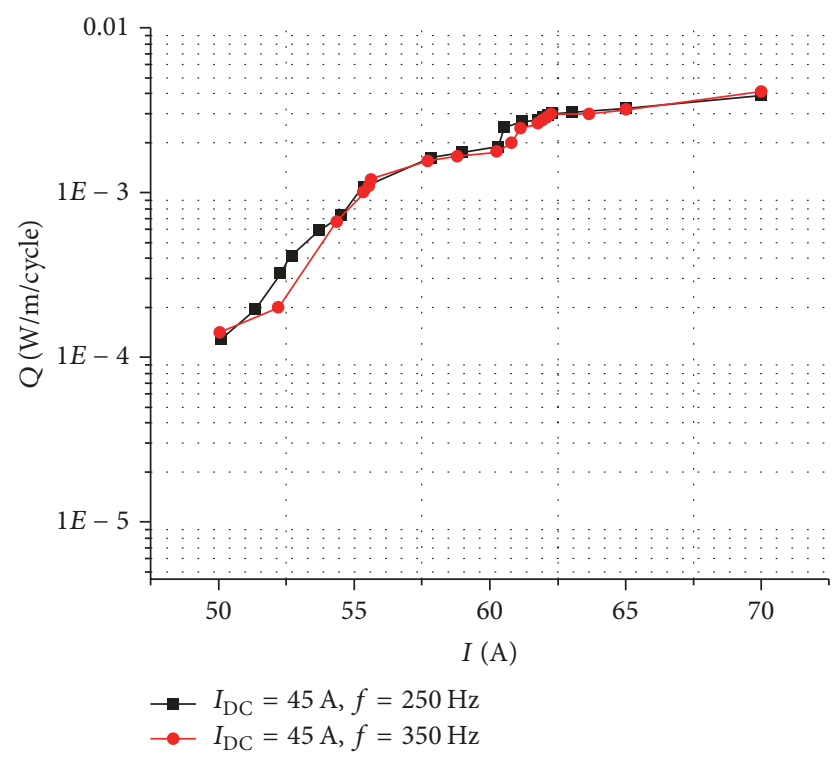

FIgure 4: The AC losses at the DC current of $45 \mathrm{~A}$ at the frequency of $250 \mathrm{~Hz}$ and $350 \mathrm{~Hz}$.

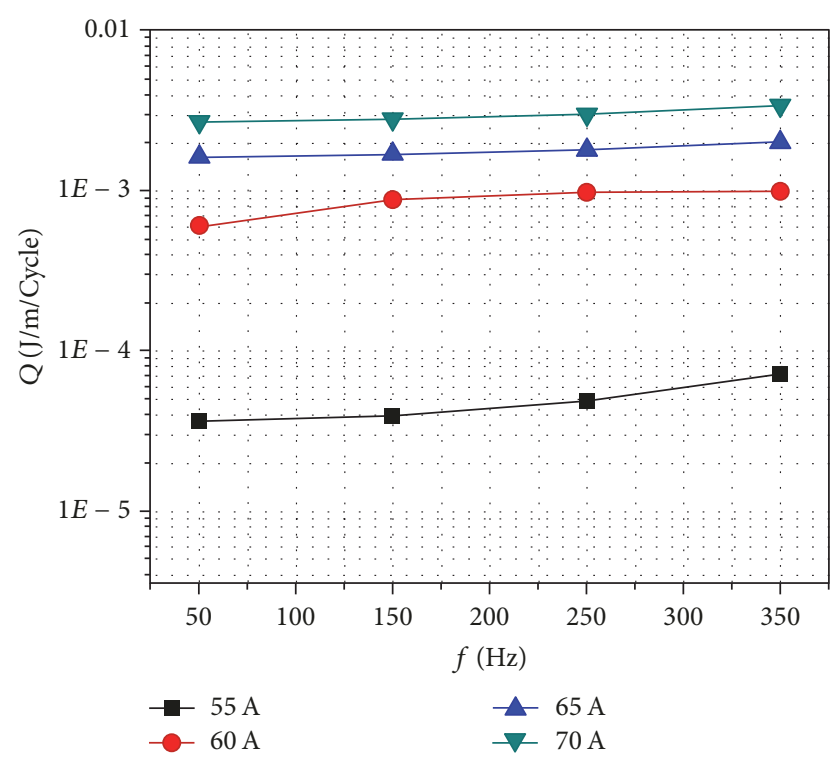

Figure 5: The AC losses at the DC current of $45 \mathrm{~A}$ at different amplitude and different frequencies.

total current of $65 \mathrm{~A}$, the $\mathrm{AC}$ loss at which the DC current was $45 \mathrm{~A}$ and the $\mathrm{AC}$ current was $20 \mathrm{~A}$ was larger than that which the DC current was $55 \mathrm{~A}$ and the AC current was $10 \mathrm{~A}$. It signified that the component of the AC current had much more effect on the AC losses. Why did it happen like that? The current distribution was the starting point. With "ripples" of larger amplitudes, it is the edges of the HTS tape that make the predominant contribution to the loss [14].

Figure 9 showed the result of the AC losses of the $0.3 \mathrm{~m}$ HTS cable. The DC current was $200 \mathrm{~A}$ and the AC ripple current ranged from $5 \mathrm{~A}$ to $25 \mathrm{~A}$. The $\mathrm{AC}$ losses were also

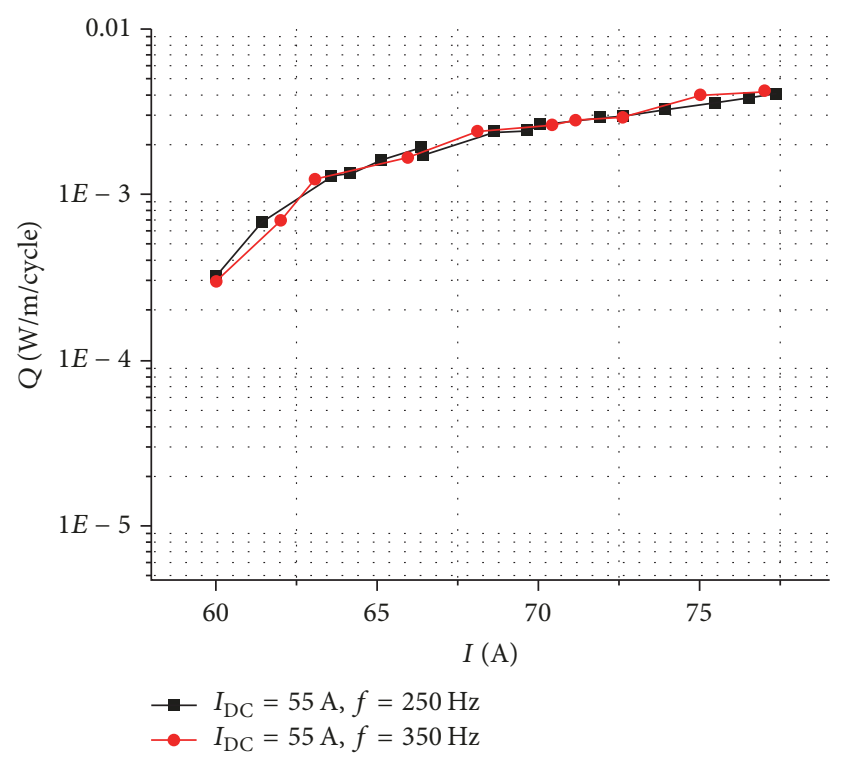

Figure 6: The AC losses at the DC current of $55 \mathrm{~A}$ at the frequency of $250 \mathrm{~Hz}$ and $350 \mathrm{~Hz}$.

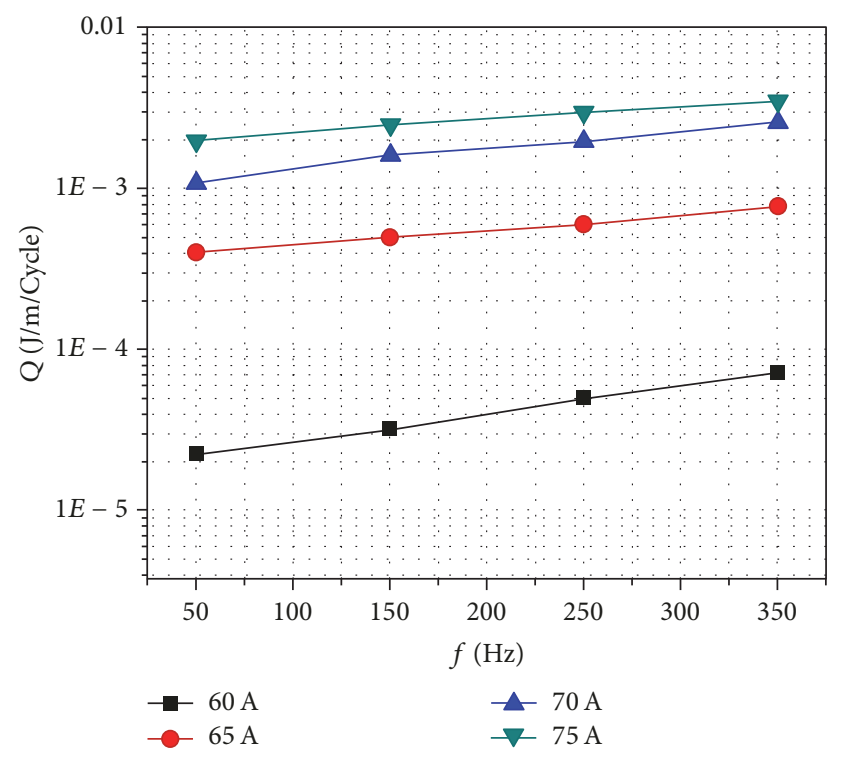

Figure 7: The AC losses at the DC current of $55 \mathrm{~A}$ at different amplitude and different frequencies.

insensitive to the frequency and increased with the AC ripple currents.

\section{Simulation Results}

To verify the measurement, a two-dimensional finite element method model based on $H$-formulation and the $E$ - $J$ power law was established. AC losses of HTS tapes were simulated, with the coexistence of DC and AC ripple currents.

The simulation result was shown in Figure 10. The comparison was made with the simulation result and the measurements. Experimental results had a little discrepancy 


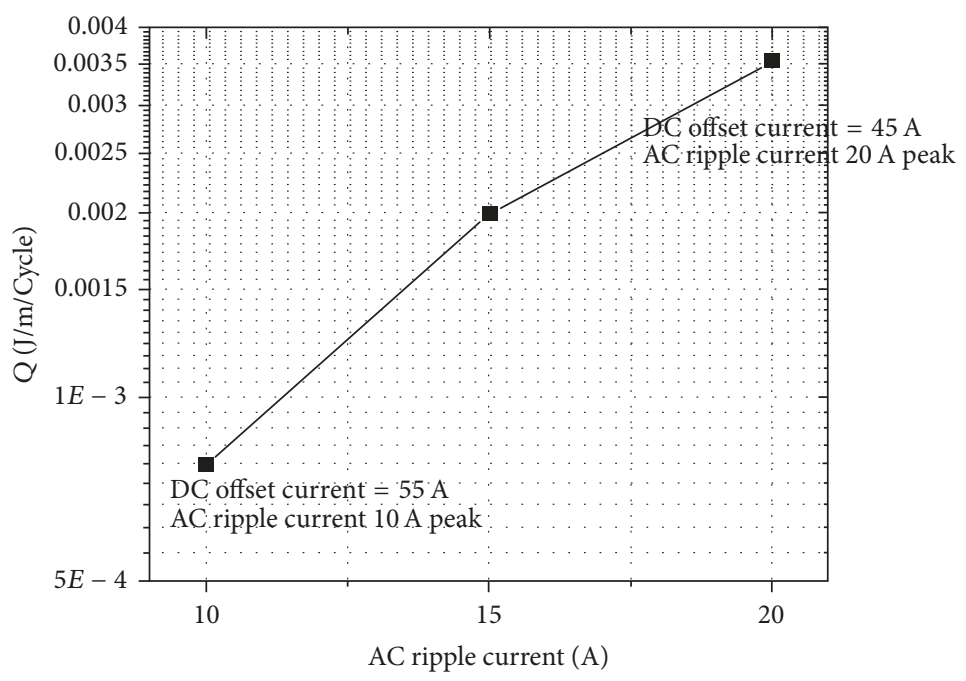

FIgURE 8: The AC losses at the same total current of $65 \mathrm{~A}$ but at the different $\mathrm{DC}$ current and the AC current.

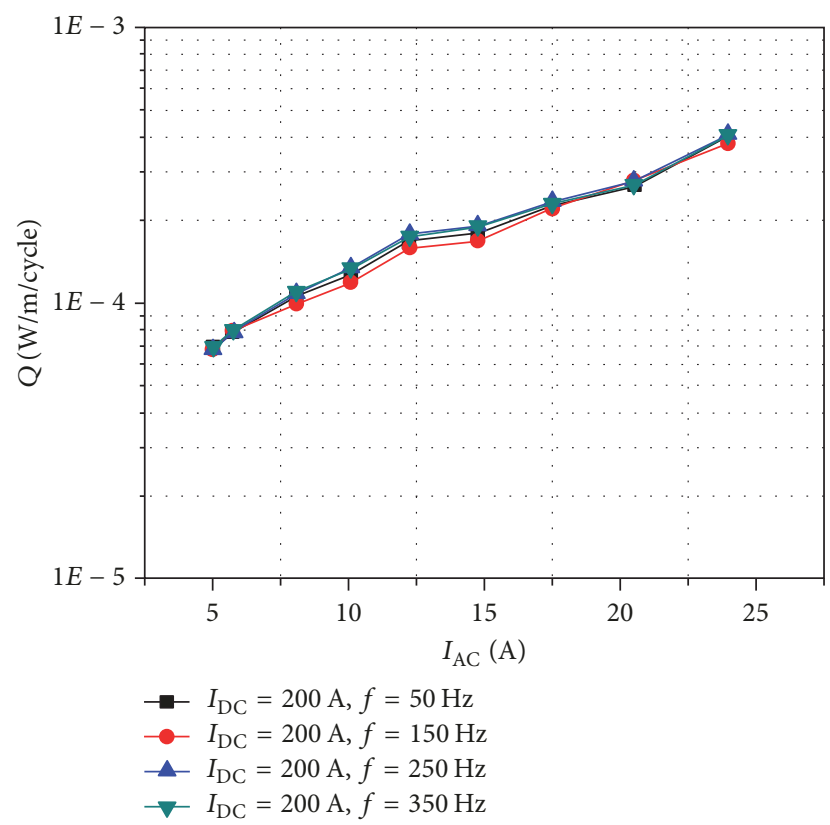

FIgURE 9: The AC losses of the $0.3 \mathrm{~m}$ HTS cable at the DC current of $200 \mathrm{~A}$ at different frequencies and different AC currents.

compared to the simulated results when the AC current was small. This discrepancy was mostly caused by the background noise during measurement when the current was small. The trends of the measured curves and simulated curve were quite similar. Moreover, the losses all increase as the total currents increase towards the critical value.

\section{Conclusion}

This paper studies AC ripple losses of HTS tapes through experiments and simulations. We found the following in the experiments: (1) AC losses increased with the amplitude of AC currents, when holding the DC current constant. (2)

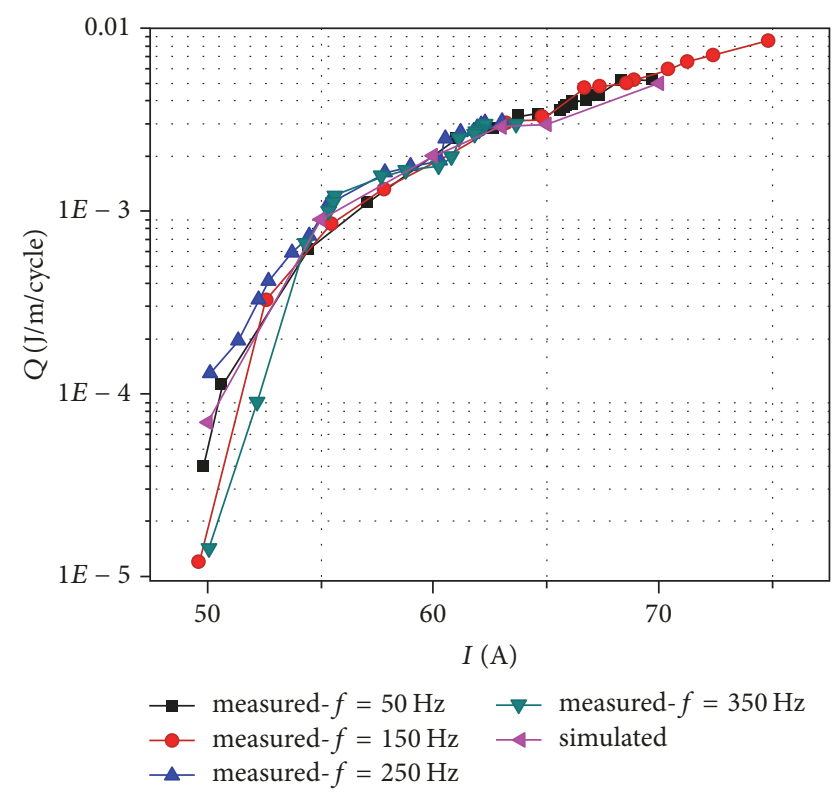

FIGURE 10: Comparisons of the measured results and the simulated results of the HTS tape.

When the sum of DC current and the amplitude of AC ripple current approaches the critical current, AC losses increased remarkably. (3) AC ripple currents had minor effects on the total AC loss when the ratio of AC to DC current was small.

\section{Disclosure}

A part of this article has been presented in the 25th International Conference on Magnet Technology.

\section{Conflicts of Interest}

The authors declare that there are no conflicts of interest. 


\section{Acknowledgments}

This work was supported by Beijing Natural Science Foundation (3162032). This paper was developed further on the basis of the suggestions from experts and researchers in the 25th International Conference on Magnet Technology. The authors would like to thank them for their help in the suggestions.

\section{References}

[1] D. Uglietti, N. Bykovsky, R. Wesche, and P. Bruzzone, "Development of HTS Conductors for Fusion Magnets," IEEE Transactions on Applied Superconductivity, vol. 25, no. 3, 2015.

[2] I. A. Kovalev, M. I. Surin, A. V. Naumov et al., "Test results of 12/18 kA ReBCO coated conductor current leads," Cryogenics, vol. 85, pp. 71-77, 2017.

[3] L. Ying, J. Xu, J. Sheng et al., "Numerical and Experimental Analysis of AC Loss of YBCO Coated Conductor Carrying DC and AC Offset Transport Current," IEEE Transactions on Applied Superconductivity, vol. 23, no. 3, pp. 5900704-5900704, 2013.

[4] M.-C. Dinh, S.-K. Kim, J.-G. Kim, M. Park, I.-K. Yu, and B. Yang, "Loss characteristic analysis of an HTS dc model cable connected to a model VSC-HVDC System," IEEE Transactions on Applied Superconductivity, vol. 23, no. 3, 2013.

[5] J.-H. Kim and S. Pamidi, "Electrical characteristics of 2G HTS tapes under DC current with AC ripple," IEEE Transactions on Applied Superconductivity, vol. 22, no. 3, 2012.

[6] J. Ogawa, S. Fukui, T. Oka et al., "Experimental investigation of loss characteristics with AC and DC offset transport current in HTS double pancake coil," IEEE Transactions on Applied Superconductivity, vol. 22, no. 3, 2012.

[7] H. Zhang, Y. Wang, C. Kan, Y. Fu, and J. Xue, "Effects of HTS Tape Arrangements on AC Loss in Self-Shielding DC HTS Cable with AC Ripple Current," IEEE Transactions on Applied Superconductivity, vol. 27, no. 4, 2017.

[8] Z. Li, K. Ryu, S. Fukui, S. D. Hwang, and G. Cha, "AC loss measurement of a short HTS cable with shield by electrical method," IEEE Transactions on Applied Superconductivity, vol. 21, no. 3, pp. 1005-1008, 2011.

[9] B. C. Robert and H. S. Ruiz, "Magnetic characteristics and AC losses of DC type-II superconductors under oscillating magnetic fields," Superconductor Science and Technology, vol. 31, no. 3, p. 035006, 2018.

[10] J. P. Murphy, N. N. Gheorghiu, T. Bullard et al., "AC loss in YBCO coated conductors at high $\mathrm{dB} / \mathrm{dt}$ measured using a spinning magnet calorimeter (stator testbed environment)," Cryogenics, vol. 86, pp. 57-69, 2017.

[11] B. J. de Bruyn, J. W. Jansen, and E. A. Lomonova, "AC losses in HTS coils for high-frequency and non-sinusoidal currents," Superconductor Science and Technology, vol. 30, no. 9, p. 095006, 2017.

[12] D. Hu, M. D. Ainslie, J. Kvitkovic et al., "Transport AC Loss Measurements of a Triangular Epoxy-Impregnated HighTemperature Superconducting Coil," IEEE Transactions on Applied Superconductivity, vol. 27, no. 4, pp. 1-6, 2017.

[13] J. Ogawa, S. Fukui, T. Oka, Y. Sano, M. Ogawa, and S. T. Ranecky, "Experimental Investigation of AC Loss Characteristics in HTS Tape With Rotating Magnetic Field," IEEE Transactions on Applied Superconductivity, vol. 27, no. 4, pp. 1-4, 2017.
[14] Z. Xu and F. Grilli, "Modelling ac ripple currents in HTS coated conductors," Superconductor Science and Technology, vol. 28, no. 10, Article ID 104002, 2015. 

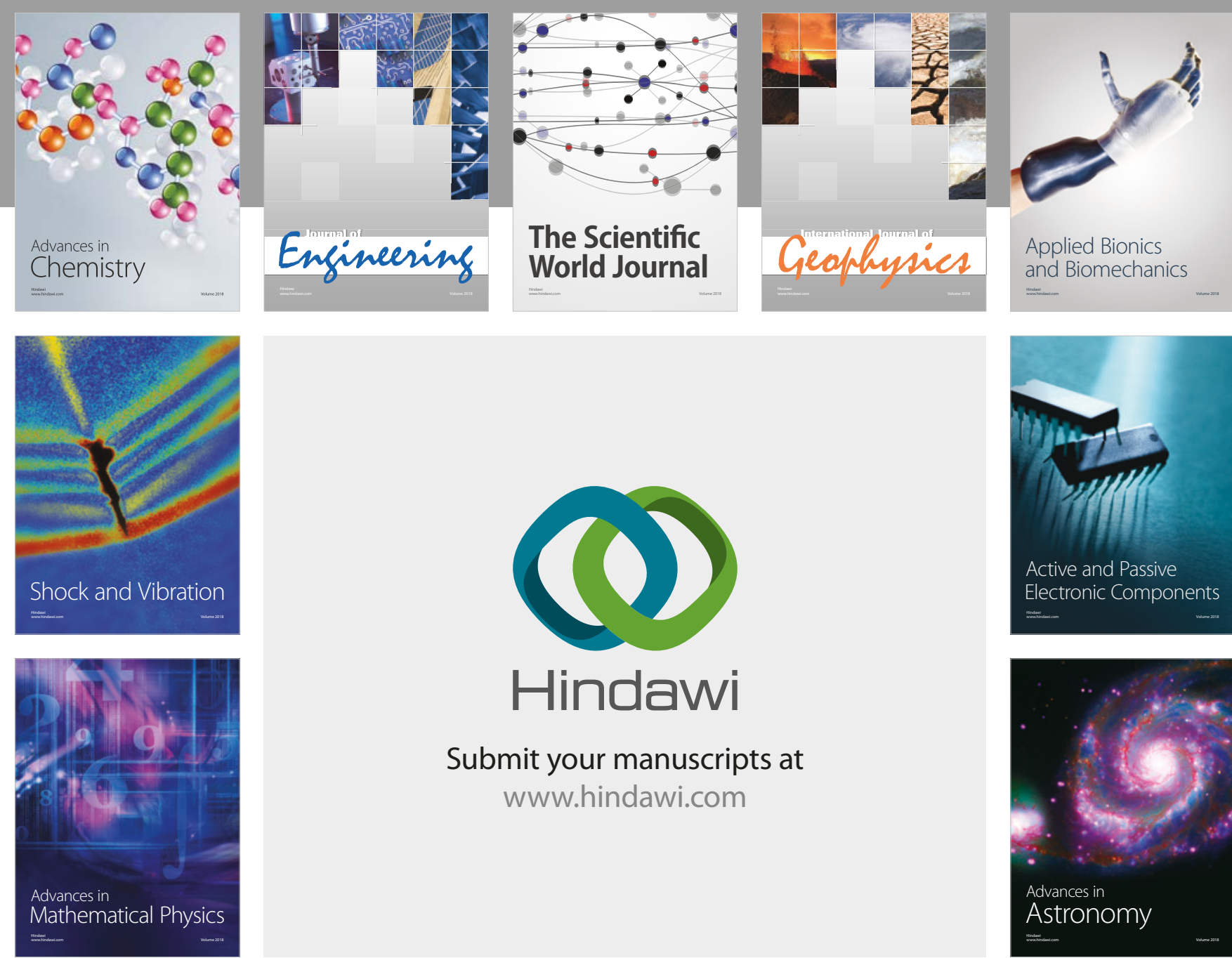

Submit your manuscripts at

www.hindawi.com

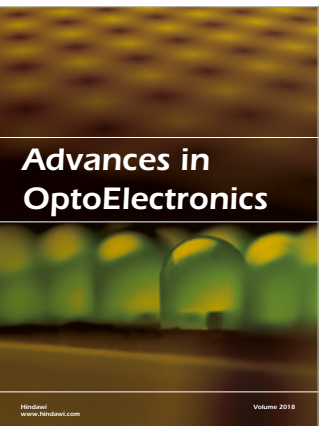

\section{Rotcting Machinery}
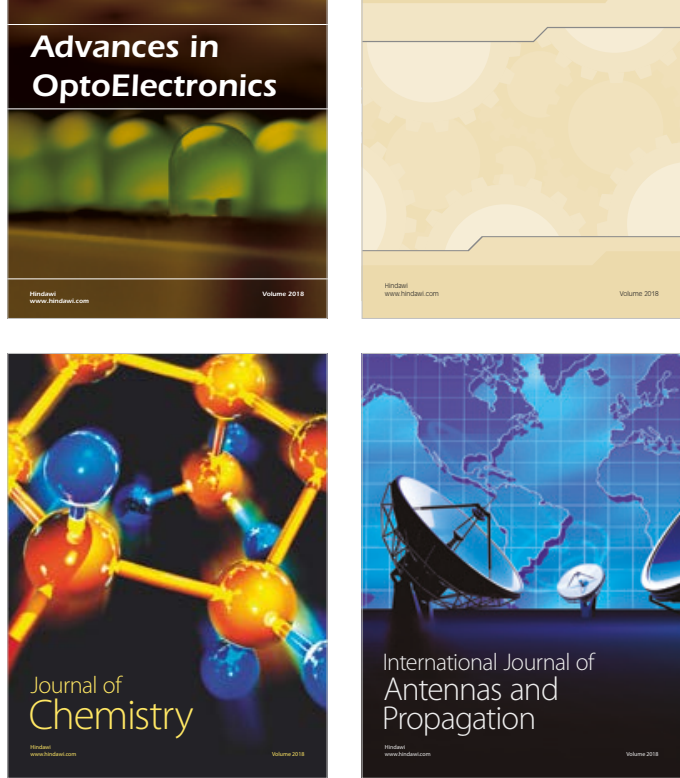

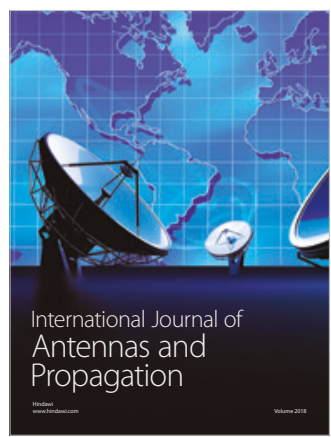

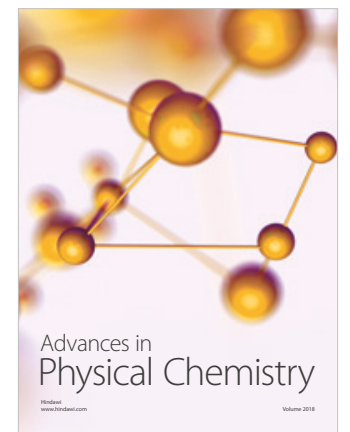

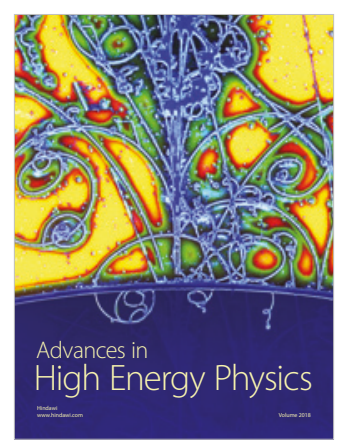

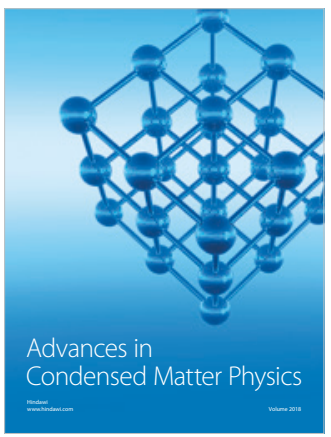

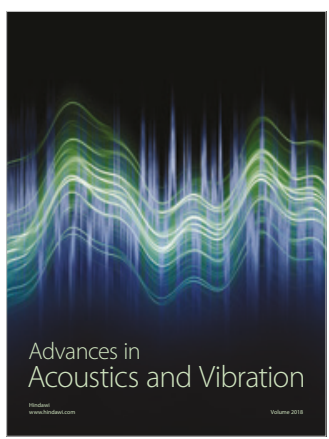

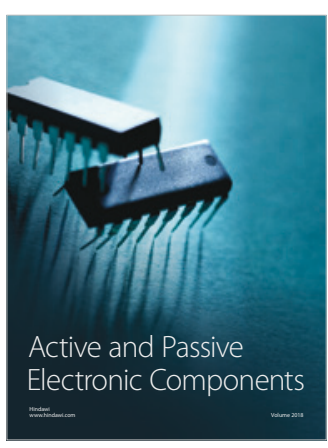
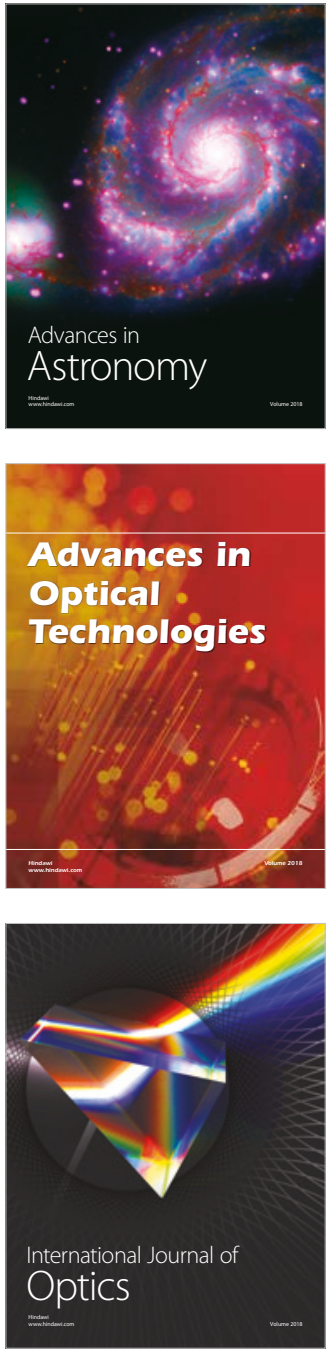